\title{
Morphological Variation of Four Tilapia Populations in Selected Reservoirs in Sri Lanka
}

\author{
S.P. Samaradivakara, N.Y. Hirimuthugoda ${ }^{1 *}$ R.H.A.N.M. Gunawardana ${ }^{1}$, R.J. Illeperuma ${ }^{2}$ \\ N.D. Fernandopulle ${ }^{2}$, A.D. De Silva ${ }^{2}$ and P.A.B.D. Alexander ${ }^{3}$
}

\author{
Faculty of Veterinary Medicine and Animal Science \\ University of Peradeniya
}

Sri Lanka

\begin{abstract}
Morphological variation among three populations of introduced Tilapia fish collected from Kurunegala, Anuradhapura and Polonnaruwa and the brood stock of Nile tilapia (Oreochromis niloticus) collected from the Udawalawe tilapia breeding centre was investigated by multivariate analysis of twenty morphometric and fourteen meristic characters. Discriminant analysis and cluster analysis of conventional morphometric measures showed a high divergence among the populations while the conventional meristic measures did not show a divergence among the populations. These results showed that the tested fish samples could be grouped into its respective collection site based on the morphometric characters. The morphometric differences between the populations may have appeared due to either genetic differences or environmental factors. The thirty-four characters, extracted from stepwise discriminant analysis played important roles in morphological differentiation.
\end{abstract}

Keywords: Meristics, morphometrics, Oreochromis niloticus

\section{INTRODUCTION}

The Nile Tilapia, Oreochromis niloticus (Linnaeus, 1758) (Cichlidae; Teleostei), is a widespread species used in tropical aquaculture. Natural populations of these fish occur in Africa and the species $O$. niloticus has been introduced to almost every tropical country in the world for aquaculture purposes. (Nyingi et al., 2009) Tilapia culture has increased in freshwater since its introduction to Sri Lanka in 1950s (De Silva, 1997). This is particularly because of its fast growth and the fact that it can be easily reproduced in many confined water bodies throughout the country. However, after decades of introduction and domestication of the fish, they have highly adapted to a wide range of geographical locations and have shown phenotypic variations with respect to the pure tilapia strains of the brood stock. This maybe due to the effects of the environment (Turana et al., 2006) or due to the hybrids evolved through extensive intrabreeding (El Serafy et al., 2007). However, it's wide spread have caused the tilapia fish to become a noxious fish, posing a threat to the native aquatic communities. In this context, natural morphometric/meristic data are of great importance for improvement of aquaculture.

Faculty of Agriculture, University of Ruhuna, Sri Lanka

Genetech Research Institute, 54, Kitulwatte Road, Colombo 08, Sri Lanka

Faculty of Veterinary Medicine and Animal Science, University of Peradeniya, Sri Lanka

Author for correspondence: nyhirimuthugoda@yahoo.com 
Morphometric and the meristic methods remains the simplest and most direct way among methods of species identification. From previous studies (Creech, 1992; Mamuris et al., 1998; Bronte et al., 1999; Hockaday et al., 2000), it is understood that the analysis of phenotypic variation in morphometric characters or meristic counts is the method most commonly used to delineate stocks of fish. Despite the advent of techniques which directly examines biochemical or molecular genetic variation, these conventional methods continues to have an important role in stock identification even to date (Swain \& Foote, 1999).

In the present study, we analyzed morphological polymorphism among hundred introduced tilapia fish obtained from locations, Kurunegala, Anuradhapura, Polonnaruwa districts. In view of the fact that tilapia fingerlings were distributed and introduced from the brood stocks of Udawalawe Tilapia breeding centre, ten samples of $O$. niloticus fish were also included as a control group from the prevailing brood stock. More specifically, the objective of this study was to investigate the morphological variations among these four tilapia populations in Sri Lanka.

\section{MATERIALS AND METHODS}

A total of 100 samples of both male and female fish were collected from reservoirs present in Kurunegala $(n=34)$ Anuradhapura $(n=25)$ and Polonnaruwa $(n=41)$. Ten samples of brood stock O. niloticus were collected from the Udawalawe Tilapia Breeding Centre (Fig. 1). Since tilapia male and female could not be differentiated morphologicaly sexing of the fish that were sampled was not carried out. After capturing the fish were transferred into boxes containing ice and brought to a laboratory in University of Peradeniya for detailed analyses.

All measurements were taken on the left side of fish. A total of 35 morphological characters were used which included 20 morphometric variables $(M)$ and 14 meristic variables $(\mathrm{m})$ which were directly counted. We examined internal meristic characters (Gil rackers, Vetebrae) as well to assess the contribution of the meristic characters to the observed phenotypic variations in the populations. The morphometric variables were measured to the nearest $0.1 \mathrm{~cm}$ using a measuring board. 


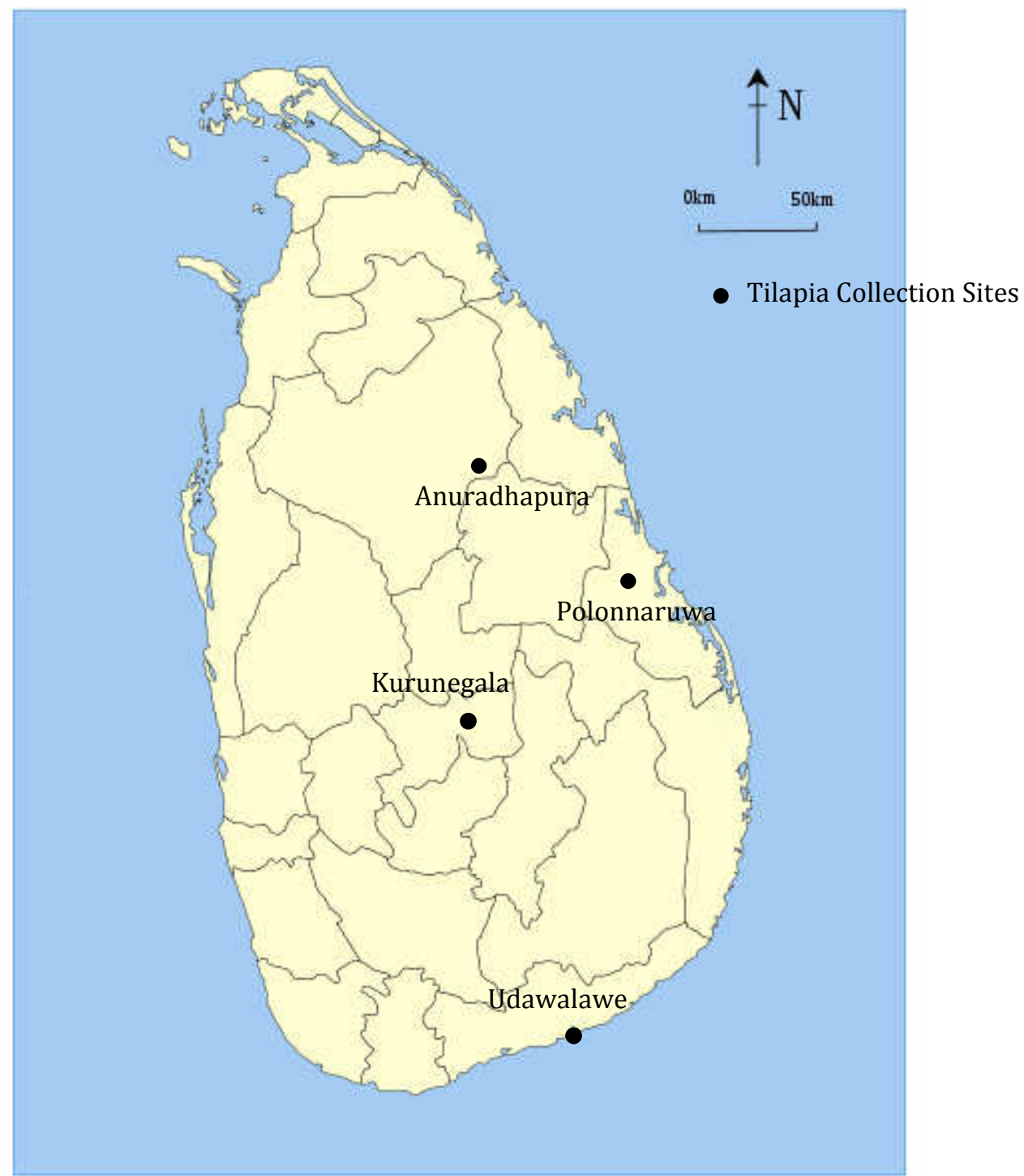

Fig. 1. Sample collections sites

The morphometric variables included Body Weight (BW), Total Length (TL), Standard Length (SL), Body Depth (BD), Length of the Head (HL), Head Depth (HD), Snout Length $(\mathrm{SnL})$, Base length of Dorsal Fin (BDF), Posterior end of the Dorsal fin to Dorsal origin of the Caudal fin (PDDC), Dorsal origin of the Caudal fin to Ventral origin of the Caudal fin (DCVC), Ventral origin of the Caudal fin to Insertion of the Anal fin (VCIA), Length of the Anal fin (LA), Base length of the Anal fin (BA), Origin of the Anal fin to Insertion of the Pelvic fin (OAIP), Length of the Pelvic fin (LP), Posterior end of the Dorsal fin to Insertion of the Anal fin (PDIA), Posterior end of the Dorsal fin to Origin of the Anal fin (PDOA), Origin of the Dorsal fin to Insertion of the LPelvic fin (ODIP), Caudal peduncle length (CL), Caudal peduncle Depth (CD) (Fig. 2). 


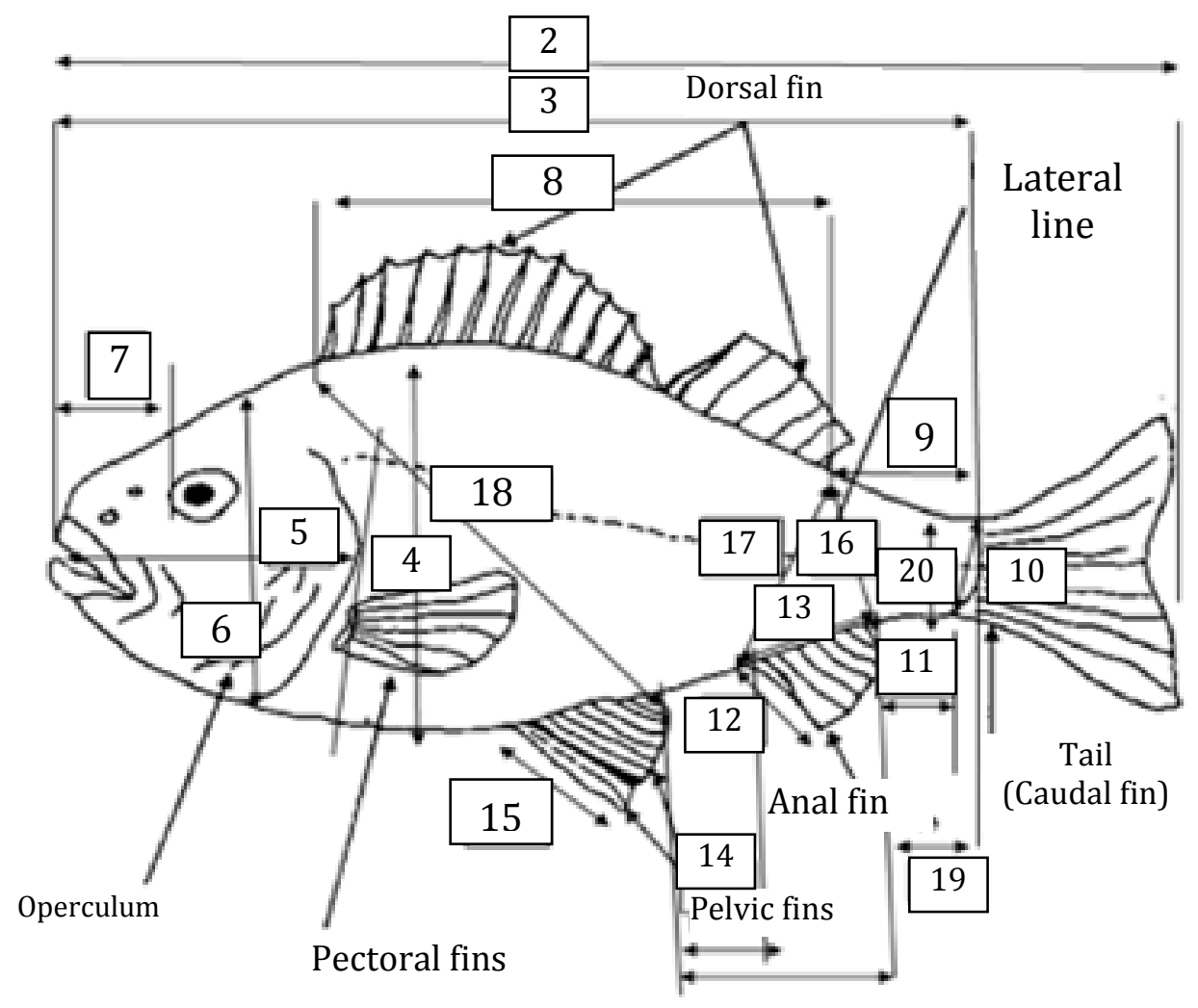

Fig. 2. Diagram of morphometric measurements

(No. 2-TL, 3-SL, 4-BD, 5-HL, 6-HD, 7-SnL, 8-BDF, 9-PDDC, 10-DCVC, 11-VCIA, 12-LA, 13-BA, 14-OAIP, 15- LP, 17- PDIA, 18-ODIP, 19-CL, 20-CD)

Meristic characters included; number of the Lateral line Scales (LS), number of the Transverse Scale (TS), number of the Predorsal Scales (PrS), number of the Postdorsal Scales (PoS), number of Scales surrounded the Caudal Peduncle (SCP), number of the Rays in the Dorsal fin (RD), number of the Spines in the Dorsal fin (SD), number of the Rays in the Anal fin (RA), number of Spines in the Anal fin (SA), number of Rays in the Pectoral fin $(\mathrm{RPec})$, number of Rays in Pelvic fin (Rpel), number of rays in Caudal fin (RC), Vertebrae (V) and Gill Rackers in the lower part of the first arch (GR).

Since meristic characters were independent of size of the fish and did not change during growth (Strauss, 1985; Murta, 2000) the raw meristic data were used in analysis. However, to avoid possible biases produced by size effects on the morphometric variables, all morphometric characters were standardized by the formula $\mathrm{AC}_{\mathrm{i}}=\log \mathrm{OC}_{\mathrm{i}}-\left[\beta *\left(\log \mathrm{TL}_{\mathrm{i}}-\right.\right.$ $\log \mathrm{MTL})$ ] (Claytor \& Mac Crimmon, 1987) where $\mathrm{AC}_{\mathrm{i}}$ is the adjusted logarithmic character measurements of the ith specimen, $\mathrm{OCi}$ is the unadjusted character measurement of the ith specimen, $\beta$ is the common within-group regression coefficient of that character against total length after the logarithmic transformation of both variables and TLi is the total length of the ith specimen; and MTL is the overall mean total length. 


\section{Statistical Analysis}

Analysis was carried out separately for morphometric and meristic characters. This is due to the two types of variables being different with respect to statistical (morphometric are continuous and meristic are discrete) and biological data (morphometric characters can be susceptible to environmental factors while most meristic characters are fixed early during the development).

Meristic characters did not show a normal distribution even after logarithmic, square root or arcsine transformations. Manly (1989) and Sokal and Rohlf (1995) have shown that discriminant analysis was robust for studying such deviations from norm, therefore multivariate analysis was carried out for meristic data collected in this study. Discriminant and cluster analysis was done separately for morphometric and meristic data. The Y values of morphometric data (standardized values) and raw meristic data for each fish samples were grouped as Location 1 - Kurunegala District, Location 2 - Anuradhapura District, Location 3 - Polonnaruwa District, Location 4- Udawalawe Tilapia breeding centre. Morphometric and meristic data of the fish belonging to each group were analyzed using SPSS software package version10 and Minitab 13.

\section{RESULTS AND DISCUSSION}

\section{Discriminant analysis of Morphometric characters}

Three canonical discriminant functions were obtained having the Eigen value of 222.471, 3.485 and 0.620 . Function 1 explains the $84.6 \%$ of the variability (Table 1 ). The larger the Eigen value, the more of the variance in the dependent variable is explained by that function. The first two discriminate functions based on the morphometric measurements together explained $97.7 \%$ of the variability $(84.6 \%$ and $13.1 \%)$.

Table 1. Summary of canonical discriminant functions

\begin{tabular}{ccccc}
\hline Function & Eigen value & Variance (\%) & Cumulative (\%) & $\begin{array}{c}\text { Canonical } \\
\text { Correlation }\end{array}$ \\
\hline 1 & 22.471 & 84.6 & 84.6 & .978 \\
2 & 3.485 & 13.1 & 97.7 & .881 \\
3 & .620 & 2.3 & 100.0 & .619 \\
\hline
\end{tabular}

According to the canonical discriminant function coefficients obtained for Morphometric data, the most influential variables for function $1 \mathrm{SL}, \mathrm{BD}, \mathrm{PDDC}, \mathrm{LA}$ and ODIP.

With respect to the discriminant function analyses on morphometric measurements, the average assignment of individuals collected from Kurunegala, Anuradhapura and Udawalwe tilapia breeding centre was $100 \%$ and assignment of individuals collected from Polonnaruwa was $95.1 \%$ suggesting each of the four populations was highly isolated from each other. 


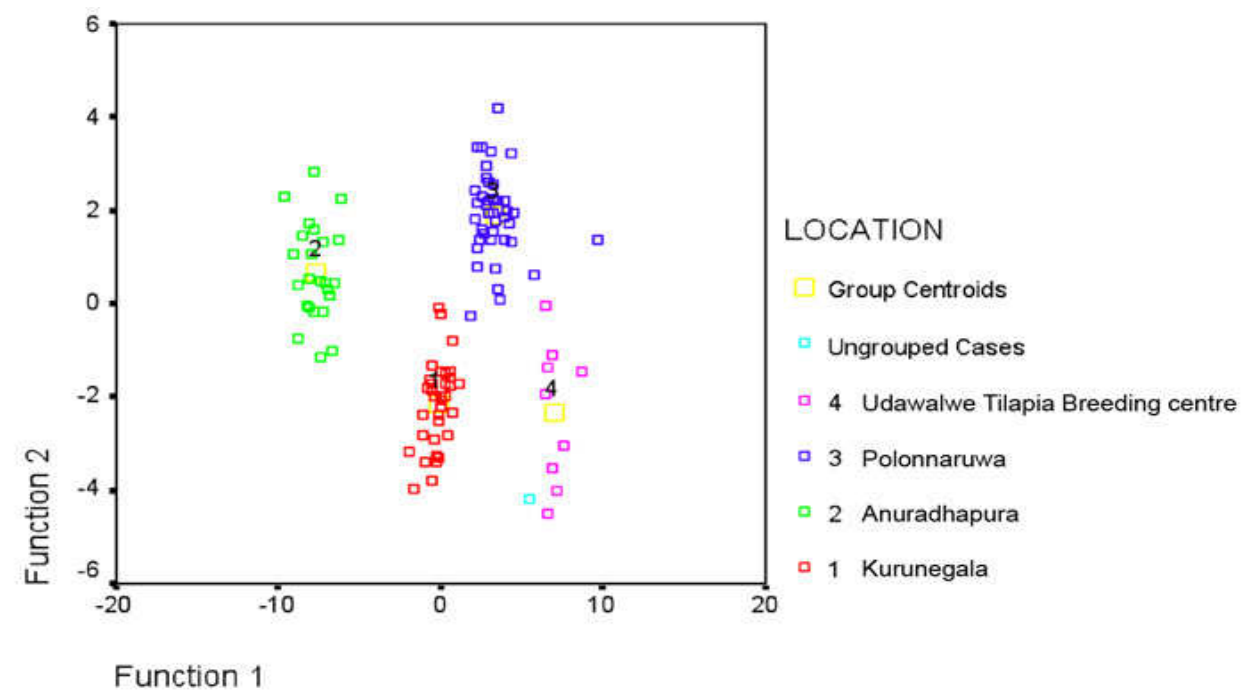

Fig. 3. Morphometric count analysis using discriminant analysis-group graph for all locations

Plots of canonical discriminant functions 1 and 2 of the morphometric measurments (Fig. 3.) showed a complete seperation between wild populations and the brood stock. Individuals from the four locations were well seperated and absolutely differenciated along the first function. 


\section{Cluster analysis of morphometric results}

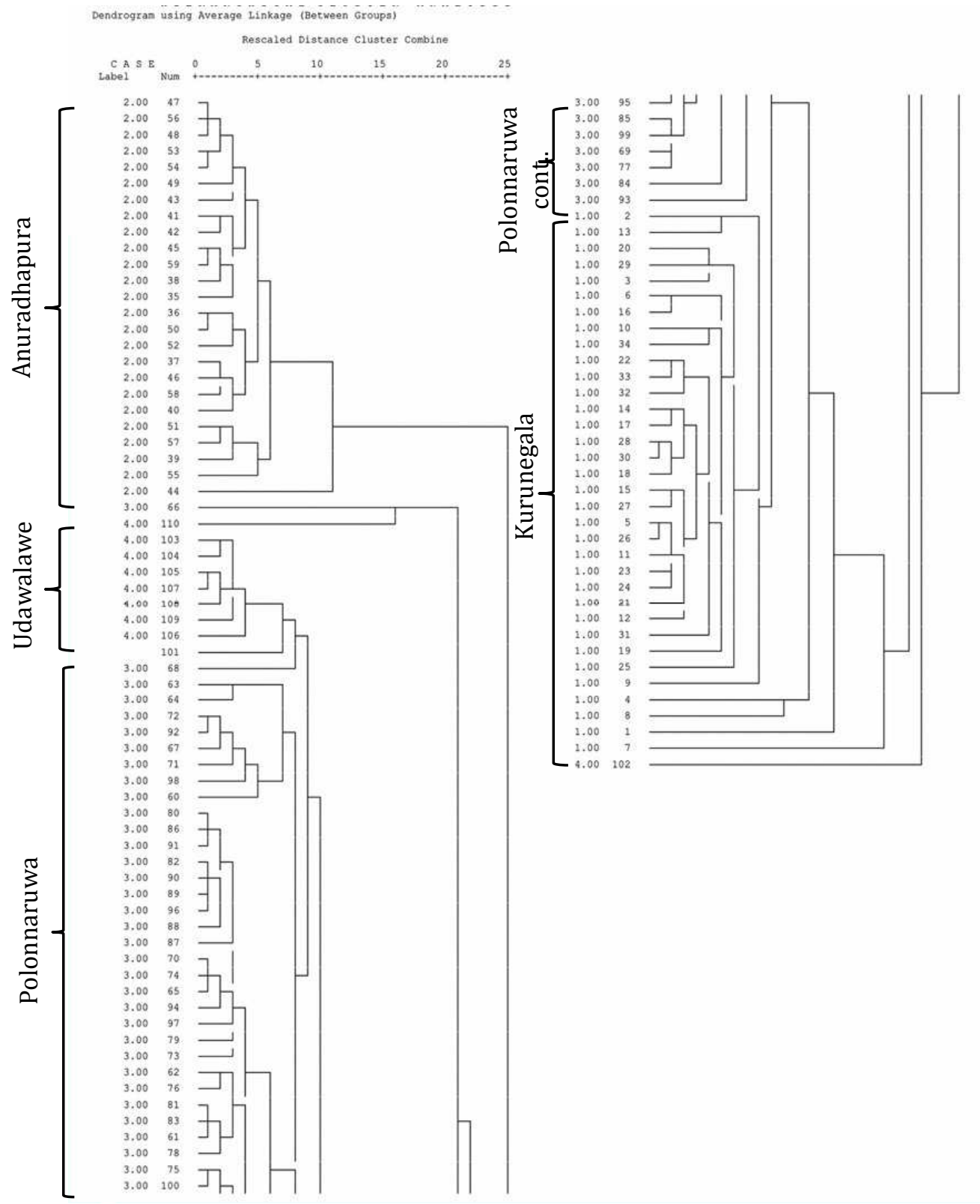

Fig. 4. Dendogram obtained for morphometric characters of the collected fish samples

The results obtained for canonical analysis for morphometric characters are presented as a dendogram in Figure 4. The four populations collected formed four groups, each group having the fish samples collected according to the locations. Therefore, a complete seperation of the four locations could be obtained. 


\section{Discriminant analysis of meristic characters}

Three canonical discriminant functions were obtained having the Eigen value of 1.615, 0.669 and 0.383 (Table 2). The first two discriminant functions based on the meristic measurements together explained $85.7 \%$ of the variability $(60.6 \%$ and $25.1 \%)$.

Table 2. Summary of canonical discriminant functions

\begin{tabular}{ccccc}
\hline Function & Eigen value & Variance (\%) & Cumulative (\%) & Canonical Correlation \\
\hline 1 & 1.615 & 60.6 & 60.6 & .786 \\
2 & .669 & 25.1 & 85.6 & .633 \\
3 & .383 & 14.4 & 100.0 & .526 \\
\hline
\end{tabular}

According to the canonical discriminant function coefficients obtained for meristic data, the most influential variables for function 1 were TS, PoS, SCP and RA.

With respect to the discriminant function analyses on meristics measurements, the average assignment of individuals collected from Kurunegala, Anuradhapura, Polonnaruwa and Udawalwe tilapia breeding centre was $64.7 \%, 80.0 \%, 92.7 \%$ and $90.0 \%$, respectively. Assigned values are lower than the values given for morphometric variables.

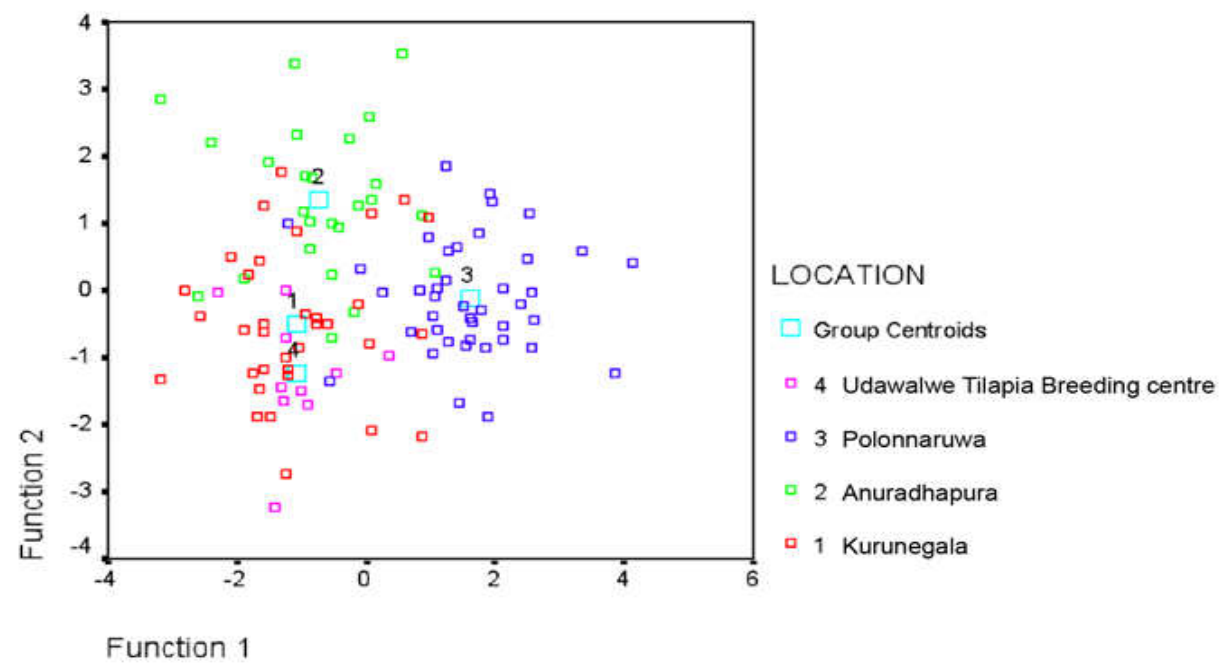

Fig. 5. Meristic counts analysis using discriminant analysis-group graph for all locations

Plots of canonical discriminant functions 1 and 2 of the meristict measurments (Fig. 5.) showed a noticable overlap of the wild populations and the brood stock. Location 1 (Kurunegala) and Location 4 (Udawalawe Tilapia breeding centre) shows the most overlapped populations.

\section{Cluster analysis of meristic data}

The results obtained for canonical analysis for meristic characters are presented as a dendogram in Figure 6. The four populations did not cluster together according to the 
locations as observed in the dendogram obtained for the morphometric characters. Therefore, a complete seperation of the four locations could not be obtained.

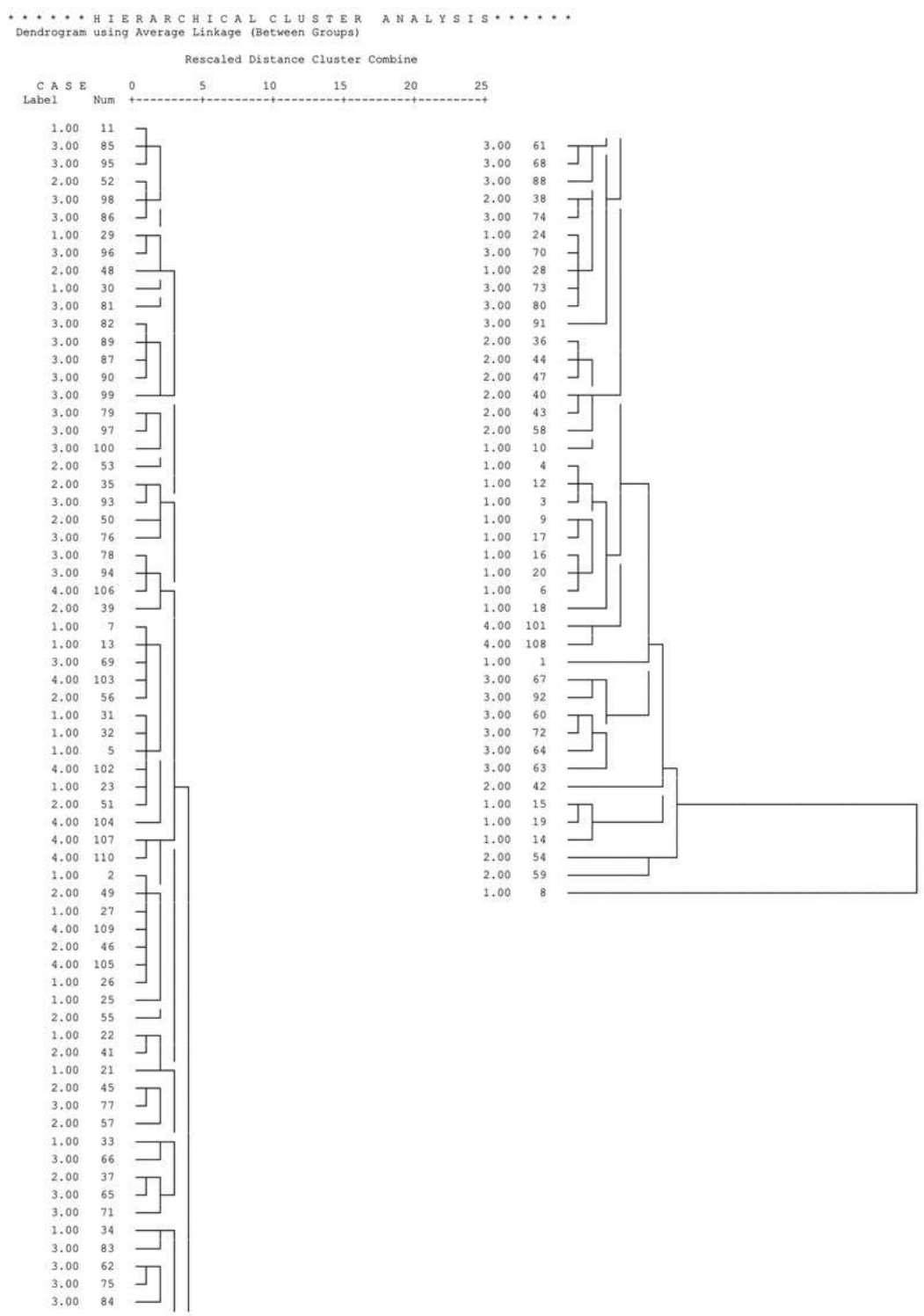

Fig. 6. Dendogram obtained from meristic characters of the collected fish

The results obtained indicate the existence of localization of tilapia fish has occurred according to the morphometric characters of the fish. Vidalis et al. (1994) argued that meristic characters may follow a predetermined variability at a very narrow range, because divergence of the meristic counts from a standard range could be fatal for the individual. Several authors have considered meristic characters less useful than the morphometric data (Misra \& Carscadden, 1987) when comparing morphological variations. Furthermore, studies on meristic characters of horse mackerel (Murta, 2000), shrimp (Munasinghe \& 
Thushari, 2010) were less informative, when compared with the morphometric ones. The results of the present study also show the existence of low or no variability in meristic characters compared to morphometric characters. From the canonical graphs (Fig. 5.) and the dendogram (Fig. 6.) it could be seen that the ranges of all meristic counts overlapped so widely among the four locations that the populations could hardly be discriminated from one location to another. In contrast analyses of morphometric characters revealed abundant variation among populations. Discriminant analyses showed obvious morphological differences between the fish collected from the different locations and the cluster analyses confirmed this result. The fish collected from the four locations clustered into four distinct groups.

Discriminant analyses determined which characters contributed significantly to the discrimination of the populations. In discriminant analyses, SL, BD, PDDC, LA and ODIP contributed heavily to canonical discriminant function 1 . Morphometrics of the head and body depth have been regarded as the most important characters for discrimination of fish populations, for example angler fish (Lophius vormernus), Pacific herring (Clupea pallasi) and Orange roughy (Hoplostethus atlanticus) (Leslie \& Grant, 1990; Schwegert, 1990; Haddon \& Willis 1995) Nevertheless, in general, fishes demonstrate greater variance in morphological traits both within and between populations than other vertebrates, and are more susceptible to environmentally induced morphological variation (Dunham et al., 1979; Allendorf, 1988; Thompson, 1991; Wimberger, 1992), which might reflect different feeding environment, prey types, food availability or other features.

In Sri Lanka, studies by Amarasinghe et al. (1983) and Chandrasoma et al. (1986) reported that the limnological parameters such as temperature, $\mathrm{pH}$, dissolved oxygen and density of plankton existing in water bodies in Sri Lanka tend to vary from one reservoir to another and area to area. In the present study tilapia were captured directly in the field using the recommended gill nets while the $O$. niloticus were collected from the breeding centre which provided contrasting growth conditions compared to that of the field in terms of environmental differentiation, each having unique ecosystem at each location. Since it is stated that the morphology of a fish or any living being is determined by the interaction between genetical and environmental factors (Barlow, 1961; Swain and Foote, 1999), it is understood that the morphometric variations occur with growth and that may change between different locations as observed in this study. For accurate assessment on how environmental parameters, which influence the most contributing morphometric characters, data should be compiled by location through out longer duration of time. The findings of the present study would significantly contribute towards designing of such a detailed study in future.

\section{CONCLUSIONS}

In summary, due to the observed high morphometric discreteness in relation to the collection sites, Kurunegala, Anuradhapura, Polonnaruwa and the Udawalwe tilapia-breeding centre may be considered as four self contained stocks/populations. Although the environmental factors may be governing to some degree for the potential phenotypic discreteness of tilapia aggregations, the detected pattern of differences show that there is some intermingling between populations. Application of molecular genetic markers such as microsatellite and mitochondrial DNA (mt-DNA) applications (Turan et al., 1998; Shaw et al., 1999) would be effective methods of examining the genetic component of phenotypic discreteness between geographic regions and facilitate the development of management recommendations. 


\section{REFERENCES}

Allendorf, F.W. (1988). Conservation biology of fishes. Conserv. Biol. 2, 145-148.

Amarasinghe, U.S., Costa, H.H. and Wijeyratne, M.J.S. (1983). Limnology and fish production potential of some reservoirs in Anuradhapura district, Sri Lanka. J. Inland Fish. 2, 14-29.

Barlow, G.W. (1961). Causes and significance of morphological variations in fishes. Syst. Zool. 10, 105-117.

Bronte, C.R., Fleischer, G.W., Maistrenko, S.G. and Pronin, N.M. (1999). Stock structure of Lake Baikal omul as determined by whole body morphology. J Fish Biol. 54, 787-798.

Chandrasoma, J., Muthukumarana, G., Pushpakumara, U. and Sreenivasan, A. (1986). Limnology and fish production in Udawalawe reservoir, Sri Lanka. J. Inland Fish. 3, 69-86

Claytor, R.R. and MacCrimmon, H.R. (1987). Partitioning size from morphometric data: a comparison of five statistical procedures used in fisheries stock identification research. Can. Tech. Rep. Fish. Aquat. Sci. No. 1531.

Creech, S. (1992). A multivariate morphometric investigation of Atherina boyeri Risso. 1810 and A. presbyter cuvier 1829 (Teloostei: Atherinidae) morphometric evidence in support of the two species. J. Fish boil. 41, 341-353.

De Silva, C.D. (1997). Genetic variation in tilapia populations in man-made reservoirs in Sri Lanka. Aqua. Int. 5, 339-349.

Dunham, A.E., Smith, G.R. and Taylor, J.N. (1979). Evidence for ecological character displacement in western American catostomic fishes. Evolution. 33. 877-896.

El Serafy, S.S., Abdel-Hamide, N.A.H., Awward, H.M. and Azab, M.S. (2007). DNA rib printing analysis of Tilapia species and their hybrids using restriction fragment length polymorphisms of the small subunit ribosomal DNA. Aqua. Res. 38, 295-303.

Hockaday S., Beddow, T.A., Stone, M., Hancock, P. and Ross, L.G. (2000). Using truss networks to estimate the biomass of Oreochromis niloticus and to investigate shape characters. J. Fish Biol. 57, 981-1000.

Haddon, M. and Willis T.J. (1995). Morphometric and Meristic comparison of orange roughy) Hoplosethus atlanticus: Trachichthyidae) from the Puysegur Bank and Lord Howe Rise, New Zealand and its implications for stock structure. Mar. Biol. 123, 19-27.

Leslie, C.C. and Grant, W.S. (1990). Lack of congruence between genetic and morphological stock structure of the Southern African anglerfish Lophius vomerinus. South Afr J. Mar. Sci. 9, 379-398.

Manly, B.F. (1989). Multivariate statistical methods: A primer. Chapman \& Hall, New York. Mamuris, Z., Apostolidis A.P., Panagiotaki P., Theodorou, A.J.and Triantaphllidis, C. (1998). Morphological variation between red mullet populations in Greece. J. Fish Biol. 52, 107-117. 
Misra, R.K. and Carscadden, J.E. (1987). A multivariate analysis of morphometrics to detect differences in populations of capelin (Mallotus villosus). J. Cons. Int. Expl. Mer. 43, 99-106.

Munasinghe, D.H.N and Thushari, G.G.N. (2010). Analysis of morphological variation of four populations of Macrobracium rosenbergii (Crustacea: Decapoda) in Sri Lanka. Cey. J Sci. (Biol. Sci.) 39, 53-60.

Murta, A.G. (2000). Morphological variation of horse mackerel (Trachurus trachurus) in the Iberian and North African Atlantic: implications for stock identification. ICES J. Mar. Sci. $57,1240-1248$.

Nyingi, D., De Vos, L., Aman, R. and Agnèse J.F. (2009). Genetic characterization of an unknown and endangered native population of the Nile tilapia Oreochromis niloticus (Linnaeus, 1758) (Cichlidae; Teleostei) in the Loboi Swamp (Kenya). Aquaculture, 297, 5763.

Schweigert, J.F. (1990). Comparison of morphometric and meristic data against truss networks for describing Pacific herring stocks. In "Fish -Marking Techniques" pp. 47- 62. (Ed.) by N.C. Parker, A.E. Giorgi, R.C. Heidinger, D.B. Jeter, E.D. Prince, G.A. Winana. American fisheries Society Sympsosium 7. American Fisheries Society, Bethesda.

Shaw, P., Turan, C., Wrigth, J., O'connell, M. and Carvalho, G.R. (1999). Microsatellite DNA analysis of population structure in Atlantic herring (Clupea harengus), with direct comparison to allozyme and mtDNA RFLP analyses. Heredity, 83, 490-499.

Sokal, R. R. and Rohlf, F. J. (1995). Biometry, 3rd ed. Freeman: San Fransisco. pp. 887.

Strauss, R.E. (1985). Evolutionary allometry and variation in body form in the South American catfish genus Corydoras (Callichthydae). Syst. Zool. 34, 381-396.

Swain, D.P. and Foote, C.J. (1999). Stocks and chameleons the use of phenotypic variation in stock identification. Fish Res. 43, 113-128

Thompson, J.D. (1991). Phenotypic plasticity as a component of evolutionary change. Trends Ecol. Evol. 6, 246-249.

Turan, C., Carvalho, G.R. and Mork, J. (1998). Molecular genetic analysis of AtlantoScandian herring (Clupea harengus) populations using allozymes and mitochondrial DNA Markers. J. Mar. Biol. Assoc. U.K. 78, 269-283.

Turana, C., Oral, M., Ozturk, B. and Duzgunes, E. (2006). Morphometric and meristic variation between stocks of Bluefish (Pomatomus saltatrix) in the Black,

Vidalis, K., Markakis, G. and Tsimenides, N. (1994). Discrimination between populations of picarel (Spicara smaris L., 1758) in the Aegean Sea, using multivariate analysis of phonetic characters. Fish Res. 30, 191-197.

Wimberger, P.H. (1992). Plasticity of fish body shape, the effects of diet, development, family and age in two species of Geophagus (Pisces: Cichlidae). Biol. J. Linn. Soc. 45, 197218. 